Check for updates

Cite this: RSC Adv., 2019, 9, 25414

\title{
Removal of refractory organics in dinitrodiazophenol industrial wastewater by an ultraviolet-coupled Fenton process
}

\begin{abstract}
Gang Ran and Qibin Li (iD *
A significant amount of biorefractory organic wastewater is generated during the production of dinitrodiazophenol (DDNP). In this study, ultraviolet light $(254 \mathrm{~nm})$ that was coupled with the Fenton (UVFenton) process was applied to treat refractory organics in DDNP industrial wastewater. The effects of key parameters (i.e., $\mathrm{H}_{2} \mathrm{O}_{2}$ dose, $\mathrm{Fe}^{2+}$ dosage, and initial $\mathrm{pH}$ ) on the treatment efficacy for DDNP industrial wastewater by the UV-Fenton process was investigated systematically. Alcohol quenching experiments were carried out to identify reactive oxygen species in the UV-Fenton process. The treatment efficacy and degradation characteristics of refractory organics were studied and compared by using control experiments. Increasing $\mathrm{H}_{2} \mathrm{O}_{2}$ and $\mathrm{Fe}^{2+}$ doses could lead to improved treatment results to a different extent. A more intense reaction and better treatment results were achieved by using the UV-Fenton process at lower $\mathrm{pH}$ conditions. Under optimal conditions of $\mathrm{H}_{2} \mathrm{O}_{2}$ dose $=7.5 \mathrm{~mL} \mathrm{~L} \mathrm{~L}^{-1}, \mathrm{Fe}^{2+}$ dosage $=$ $0.05 \mathrm{mM}$, and initial $\mathrm{pH}=5.0$, the pseudo-first order constants $k$ for chemical oxygen demand removal and color number removal were $0.18 \mathrm{~min}^{-1}$ and $1.24 \mathrm{~min}^{-1}$, and the chemical oxygen demand and color number removal efficiencies were $74.24 \%$ and $99.94 \%$, respectively. The treatment results for the UVFenton process were better than other processes under the same conditions, and a significant synergetic effect was observed for the UV-Fenton process. Alcohol quenching experiments indicated that the predominant reactive oxygen species in the UV-Fenton process was the hydroxyl radical $(\cdot \mathrm{OH})$. Because more $\cdot \mathrm{OH}$ was produced, the UV-Fenton process exhibited a much better treatment performance in degrading and destroying organic structures (i.e., benzene rings, $-\mathrm{NO}_{2}$, and $-\mathrm{N}=\mathrm{N}-$ ). Furthermore, the biodegradability indicated by the biological oxygen demand/chemical oxygen demand ratio was improved considerably to 0.48 from 0.054 . The good treatment performance by UV-Fenton allowed for a more efficient electrical energy consumption compared with the UV and $U V-\mathrm{H}_{2} \mathrm{O}_{2}$. This study provides a theoretical reference for DDNP industrial wastewater treatment by using the UV-Fenton process.
\end{abstract}

Received 28th June 2019

Accepted 6th August 2019

DOI: $10.1039 /$ c9ra04905c

rsc.li/rsc-advances

\section{Introduction}

Dinitrodiazophenol (DDNP) has been used extensively in detonators and primary explosives owing to its great initiating performance and abundant resources..$^{1-3}$ The most common DDNP production process includes three steps: neutralization, reduction, and diazo processes. During production, 200-300 kg wastewater will be generated for every $1 \mathrm{~kg}$ of DDNP that is produced. ${ }^{2,4,5}$ DDNP industrial wastewater contains various hazardous compounds, such as nitrophenol, nitro compounds, and other biorefractory substances. ${ }^{2,3}$ Because of their complex constitution, intense color, and difficulty of treatment, hazardous organic compounds in DDNP industrial wastewater will have a severe impact on animals and human beings because of their teratogenic, carcinogenic, and mutagenic effects. ${ }^{4,6}$ Nitrophenols in wastewater have been listed as

Faculty of Geosciences and Environmental Engineering, Southwest Jiaotong University, Chengdu 611756, China.E-mail: liqb@home.swjtu.edu.cn a priority pollutant by the Ministry of Ecology and Environment of the People's Republic of China. Therefore, proper treatment for DDNP industrial wastewater that contains various hazardous organic compounds is required urgently.

Treatment methods for DDNP industrial wastewater and other explosive production wastewater include the adsorption method, persulfate activation process, combined $\mathrm{Fe}^{0} / \mathrm{air}$ and Fenton process, electrolysis method, and $\mathrm{Fe} / \mathrm{Cu}-e n h a n c e d$ ozonation process. ${ }^{2-7}$ Satisfactory treatment results were obtained by using all of these methods. However, drawbacks still remain in these processes, such as desorption wastewater, increase of salinity of the treated effluent, iron sludge production, and heavy metal leaching. These methods can treat DDNP industrial wastewater, but some shortcomings restrict their application. In summary, a rapid and efficient method for DDNP industrial wastewater treatment is required.

Advanced oxidation processes (AOPs) have attracted widespread attention in wastewater treatment and groundwater remediation. ${ }^{8-16}$ AOPs utilize mainly the produced reactive 
oxygen species (ROS) to oxidize refractory organic matters. $\cdot \mathrm{OH}$ (oxidation potential of $2.8 \mathrm{~V}$ ) can oxidize substrates nonselectively and result in rapid organic pollutant reaction (second reaction rate constant of $10^{7}$ to $\left.10^{10} \mathrm{~L}(\mathrm{~mol} \mathrm{~s})^{-1}\right) \cdot{ }^{16-20}$ Many technologies can produce $\cdot \mathrm{OH}$, including the Fenton method, UV- $\mathrm{H}_{2} \mathrm{O}_{2}$, and the UV-Fenton process. ${ }^{21-26}$ Among the methods, the UV-Fenton process is a developed process based on the traditional Fenton process. More $\cdot \mathrm{OH}$ can be produced by $\mathrm{Fe}^{2+}$ catalyzing $\mathrm{H}_{2} \mathrm{O}_{2}$ under UV conditions, and the utilization efficiency of $\mathrm{H}_{2} \mathrm{O}_{2}$ will also be improved..$^{24,27,28} \mathrm{Fe}^{3+}$ can be transformed to $\mathrm{Fe}^{2+}$ by UV to catalyze $\mathrm{H}_{2} \mathrm{O}_{2} \cdot{ }^{24,28}$ The UV-Fenton process is very efficient in organic wastewater treatment. ${ }^{29,30}$ However, treatment of DDNP industrial wastewater by using the UV-Fenton process has rarely been reported.

This study applied the UV-Fenton process to the treatment of refractory organics in DDNP industrial wastewater. The objectives of this study were to (1) study the effects of $\mathrm{H}_{2} \mathrm{O}_{2}$ dose, $\mathrm{Fe}^{2+}$ dosage, and initial $\mathrm{pH}$ on treatment efficacy for DDNP industrial wastewater by the UV-Fenton process; (2) confirm the advantage of the UV-Fenton process by carrying our control experiments under the same optimum conditions; (3) identify the predominant ROS in the UV-Fenton process and its contribution to organics degradation; (4) reveal the degradation characteristics of refractory organics in DDNP industrial wastewater by using ultraviolet-visible spectroscopy (UV-Vis); and (5) investigate the improvement in biodegradability presented by the biological oxygen demand/chemical oxygen demand ratio and electrical energy consumption of the UVFenton process. This study aimed to provide useful and theoretical reference for DDNP industrial wastewater treatment.

\section{Materials and methods}

\subsection{DDNP industrial wastewater}

DDNP industrial wastewater was collected from a DDNP production factory in southwest China. The wastewater was dark brown and had no odor. After collection, the DDNP industrial wastewater was sealed immediately and stored in the dark at a constant $4{ }^{\circ} \mathrm{C}$. The chemical oxygen demand (COD) concentration of the wastewater was $409.64 \mathrm{mg} \mathrm{L}^{-1}$, the $\mathrm{pH}$ was 7.43 , the color number $(\mathrm{CN})$ was 2.12 , and the biological oxygen demand (BOD)/COD ratio was 0.054 , which indicates that the biodegradability of the DDNP industrial wastewater was extremely low.

\subsection{Experimental setup}

The reactor was custom-built from glass to prevent UV light from escaping. The experimental setup included a glass container, a UV lamp, a pH detector, and a reagents input pipe. Fig. 1 shows an experimental diagram of the UV-Fenton process.

\subsection{Chemicals}

Hydrogen peroxide $\left(\mathrm{H}_{2} \mathrm{O}_{2}, 30 \% \mathrm{v} / \mathrm{v}\right)$, ferrous persulfate $\left(\mathrm{FeSO}_{4}\right)$, potassium dichromate $\left(\mathrm{K}_{2} \mathrm{Cr}_{2} \mathrm{O}_{7}\right)$, tert-butyl alcohol (TBA), and other reagents were of analytical grade and were from Chron Chemical Factory (Chengdu, China). All reagents were used

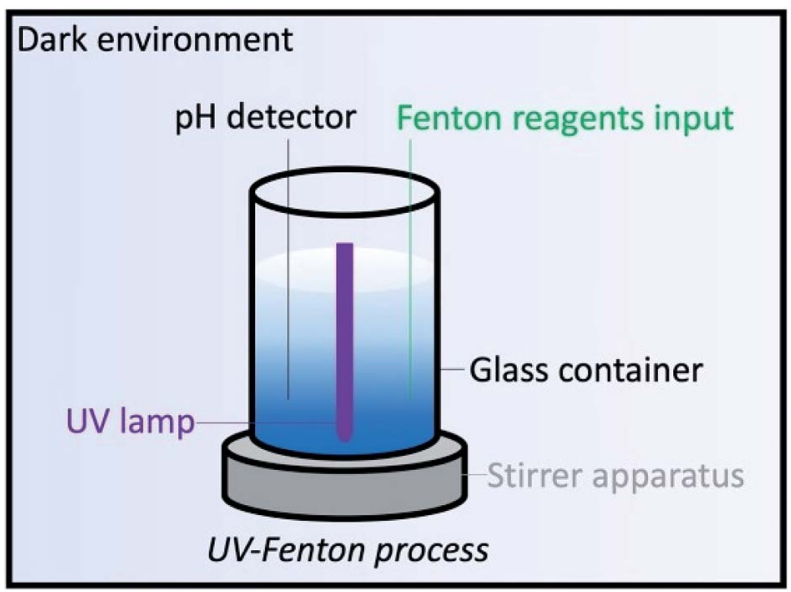

Fig. 1 Experimental diagram of UV-Fenton process.

without further purification. Ultrapure water was used throughout the experiment.

\subsection{Experimental procedure}

First, $400 \mathrm{~mL}$ DDNP industrial wastewater was transferred into the reactor and its $\mathrm{pH}$ was adjusted by using $\mathrm{NaOH}$ and $\mathrm{H}_{2} \mathrm{SO}_{4}$ $(0.5 \mathrm{mM})$. Second, a certain dose of Fenton reagents $\left(\mathrm{H}_{2} \mathrm{O}_{2}\right.$ and $\mathrm{FeSO}_{4}$ ) was added into the container to initiate the Fenton reaction. The stirrer apparatus and UV lamp were turned on immediately. At a certain reaction time $(5,10,20,30,40,50$, and $60 \mathrm{~min}$ ), a $20 \mathrm{~mL}$ sample was taken for further tests. After the reaction, the stirrer apparatus and UV lamp were turned off, and an appropriate dose of catalase (C-9322, Sigma-Aldrich, Shanghai, China) was added to each sample to eliminate residual $\mathrm{H}_{2} \mathrm{O}_{2}$ that could affect further tests.

\subsection{Analytical methods}

The COD concentration determination for each sample was performed using a microwave sealed digestion method according to the "Standard Method". ${ }^{31}$ The $\mathrm{pH}$ of each sample was measured by using a pH meter (Phs-25, Fangzhou Co., Chengdu, China). The absorbance of each sample was determined by UV-Vis spectroscopy (Lambda 950, Perkin-Elmer, Shanghai, China) with a scan range from $240 \mathrm{~nm}$ to $600 \mathrm{~nm}$ and a scan interval of $2 \mathrm{~nm}$. The $\mathrm{CN}$ was calculated according to eqn (1) where $A_{436}, A_{525}$, and $A_{620}$ represent the absorbance at $436 \mathrm{~nm}, 525 \mathrm{~nm}$, and $620 \mathrm{~nm}$, respectively.

$$
\mathrm{CN}=\frac{A_{436}{ }^{2}+A_{525}{ }^{2}+A_{620}{ }^{2}}{A_{436}+A_{525}+A_{620}}
$$

A pseudo-first-order model was used to characterize the removal rate of $\mathrm{COD}$ and $\mathrm{CN}$ according to the operational variables (i.e., $\mathrm{H}_{2} \mathrm{O}_{2}$ dose, $\mathrm{Fe}^{2+}$ dosage, and initial $\mathrm{pH}$ ) according to eqn (2) where $C_{t}$ and $C_{0}$ represent the COD or CN concentration at time $t$ min and at time $0 \mathrm{~min}$, respectively; $t$ (min) is the reaction time; and $k\left(\mathrm{~min}^{-1}\right)$ is the pseudo-first-order constant. 


$$
\ln \frac{C_{t}}{C_{0}}=-k t
$$

The synergetic effect (SE) was evaluated according to eqn (3).$^{32}$ A higher SE (>1) indicates a stronger synergetic effect. In eqn (3), SE represents the synergetic effect; $k_{\text {(combination process) }}$ is the pseudo-first-order constant $k$ in the UV-Fenton process; and $\sum k_{\text {(single process) }}$ is the sum of the $k$ values in the $\mathrm{UV}, \mathrm{H}_{2} \mathrm{O}_{2}$, and $\mathrm{Fe}^{2+}$ processes.

$$
F=\frac{k_{(\text {combination process })}}{\sum k_{(\text {single process })}}
$$

The electrical energy consumption (EEC) was evaluated according to eqn (4), ${ }^{33}$ where $P(\mathrm{~kW})$ is the UV lamp power; $t$ (min) is the reaction time; $V(\mathrm{~L})$ is the volume of wastewater; $C_{\mathrm{i}}$ and $C_{\mathrm{f}}$ are the initial and final COD concentrations, respectively; and 60 converts min to $\mathrm{h}$.

$$
\mathrm{EEC}=\frac{P \times t \times 10^{3}}{V \times 60 \times \log \left(C_{0} / C_{t}\right)}
$$

\section{Results and discussion}

\subsection{Effect of key parameters}

3.1.1. Effect of $\mathrm{H}_{2} \mathrm{O}_{2}$ dose. $\mathrm{H}_{2} \mathrm{O}_{2}$ is the oxidant reagent in the UV-Fenton process, and is important in affecting the treatment efficacy. The effect of $\mathrm{H}_{2} \mathrm{O}_{2}$ dose was investigated and is shown in Fig. 2.

As shown in Fig. 2, the treatment efficiencies increased with an increase in $\mathrm{H}_{2} \mathrm{O}_{2}$ dose. When the $\mathrm{H}_{2} \mathrm{O}_{2}$ dose increased to $10 \mathrm{~mL} \mathrm{~L}^{-1}$ from an initial $2.5 \mathrm{~mL} \mathrm{~L}^{-1}$, the COD and $\mathrm{CN}$ removal efficiencies increased from $52.31 \%$ and $79.91 \%$ to $76.28 \%$ and $99.94 \%$ at $60 \mathrm{~min}$, respectively, and the $k_{\mathrm{COD}}$ and $k_{\mathrm{CN}}$ increased from 0.11 and $0.27 \mathrm{~min}^{-1}$ to 0.18 and $1.29 \mathrm{~min}^{-1}$, respectively. Reaction rate $k$ for COD and $\mathrm{CN}$ increased more slowly. A higher $\mathrm{H}_{2} \mathrm{O}_{2}$ dose can enhance the treatment efficacy of the UV-Fenton process. $\mathrm{OH}$ will be produced from $\mathrm{UV}$ and $\mathrm{Fe}^{2+}$-catalyzing $\mathrm{H}_{2} \mathrm{O}_{2}$ (eqn (5) and (6)). ${ }^{29,34,35}$ However, an overdose of $\mathrm{H}_{2} \mathrm{O}_{2}$ will also react with $\cdot \mathrm{OH}$ and compete with organic substrates that react with $\cdot \mathrm{OH}$, which results in a less significant increase in treatment efficacy. Therefore, $7.5 \mathrm{~mL} \mathrm{~L}^{-1}$ will be a suitable $\mathrm{H}_{2} \mathrm{O}_{2}$ dose to avoid wasting oxidant.

$$
\mathrm{Fe}^{2+}+\mathrm{H}_{2} \mathrm{O}_{2} \rightarrow \mathrm{Fe}^{3+}+\mathrm{OH}^{-}+\mathrm{HO}^{\cdot}
$$
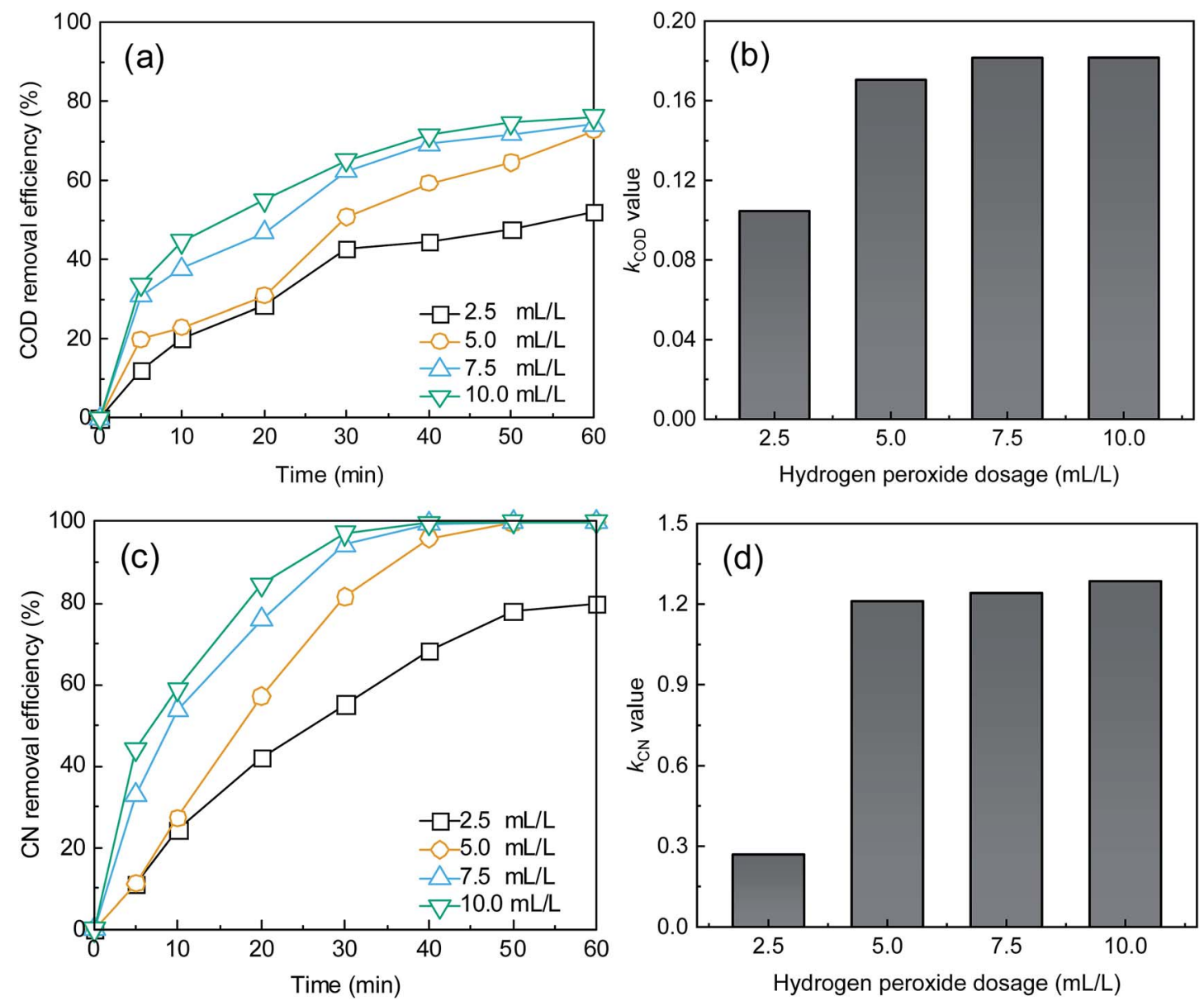

Fig. 2 Effect of $\mathrm{H}_{2} \mathrm{O}_{2}$ dose on (a) COD removal, (c) $\mathrm{CN}$ removal, and $k$ for (b) $\mathrm{COD}$ and (d) $\mathrm{CN}$. Conditions: Fe $\mathrm{Fe}^{2+}$ dosage $=0.05 \mathrm{mM}$ and initial $\mathrm{pH}$ $=5.0$. 


$$
\mathrm{UV}+\mathrm{H}_{2} \mathrm{O}_{2} \rightarrow \mathrm{HO}^{\circ}+\mathrm{HO}^{\circ}
$$

3.1.2. Effect of $\mathbf{F e}^{2+}$ dosage. $\mathrm{Fe}^{2+}$ is required to initiate the Fenton reaction, and its dosage has an important impact on the treatment efficiency. The effect of $\mathrm{Fe}^{2+}$ dosage is shown in Fig. 3.

As shown in Fig. 3, the removal efficiencies of COD and CN and $k_{\mathrm{COD}}$ and $k_{\mathrm{CN}}$ increased with an increase in $\mathrm{Fe}^{2+}$ dosage. At $60 \mathrm{~min}$, the COD and CN removal were $78.98 \%$ and $99.99 \%$, respectively, when the $\mathrm{Fe}^{2+}$ dose was $0.075 \mathrm{mM}$. The $k_{\mathrm{COD}}$ and $k_{\mathrm{CN}}$ reached their highest values of 0.19 and $1.53 \mathrm{~min}^{-1}$, respectively. In the UV-Fenton process, $\mathrm{Fe}^{2+}$ can catalyze $\mathrm{H}_{2} \mathrm{O}_{2}$ to produce ROS, which degrades most organic matters. The generated $\mathrm{Fe}(\mathrm{OH})^{2+}$ can be transformed to $\mathrm{Fe}^{2+}$ and $\cdot \mathrm{OH}$ in $\mathrm{UV}$ light (eqn (7)), ${ }^{29,35}$ and a better treatment efficacy can be obtained. Some research has indicated that $\mathrm{Fe}^{2+}$ of an extremely high concentration will capture ROS and reduce the removal efficiency, ${ }^{25,26,36}$ however, this result was not found in this study. Above all, $0.5 \mathrm{mM} \mathrm{Fe}^{2+}$ can be selected as an optimal parameter.

$$
\mathrm{Fe}(\mathrm{OH})^{2+} \stackrel{h v}{\longrightarrow} \mathrm{Fe}^{2+}+\mathrm{HO}^{\circ}
$$

3.1.3. Effect of initial $\mathbf{p H}$. Previous studies have reported that the formation of $\mathrm{Fe}^{2+}$ and $\mathrm{H}_{2} \mathrm{O}_{2}$ can be influenced by the initial $\mathrm{pH},{ }^{11}$ and thus, the treatment efficiency also varies. The effect of initial pH was plotted in Fig. 4.

As shown in Fig. 4, the best treatment efficiency was obtained when the initial $\mathrm{pH}$ was 3 . The removal efficiencies of COD and $\mathrm{CN}$ were $82.65 \%$ and $99.99 \%$, and those for the $k_{\mathrm{COD}}$ and $k_{\mathrm{CN}}$ were 0.22 and $1.63 \mathrm{~min}^{-1}$, respectively, at an initial $\mathrm{pH}$ of 3 and a reaction time of $60 \mathrm{~min}$. An increase in $\mathrm{pH}$ leads to a decrease in treatment efficiency. When the initial $\mathrm{pH}$ reached 11 , the COD removal efficiency decreased to $54.03 \%$ and likewise, the $k_{\mathrm{COD}}$ and $k_{\mathrm{CN}}$ decreased considerably to 0.10 and $0.47 \mathrm{~min}^{-1}$. The inhibition effect of the high pH condition may be contributed to the decomposition of $\mathrm{H}_{2} \mathrm{O}_{2}$, and iron colloids will be generated in an alkaline environment. However, the final $\mathrm{CN}$ removal efficiency was high for a pH range of 3 to 11 , possibly because the $-\mathrm{N}=\mathrm{N}$ - group will be destroyed by alkali and partially by UV light. Thus, a high CN removal efficiency was obtained for a wide range of initial $\mathrm{pH}$ values.

\subsection{Control experiments}

To study the advantages of the UV-Fenton process in treating DDNP industrial wastewater, six control experiments (single $\mathrm{Fe}^{2+}$, single $\mathrm{H}_{2} \mathrm{O}_{2}$, single UV, UV-Fe ${ }^{2+}$, Fenton, UV- $\mathrm{H}_{2} \mathrm{O}_{2}$ ) were conducted and their treatment efficacies were compared as shown in Fig. 5.
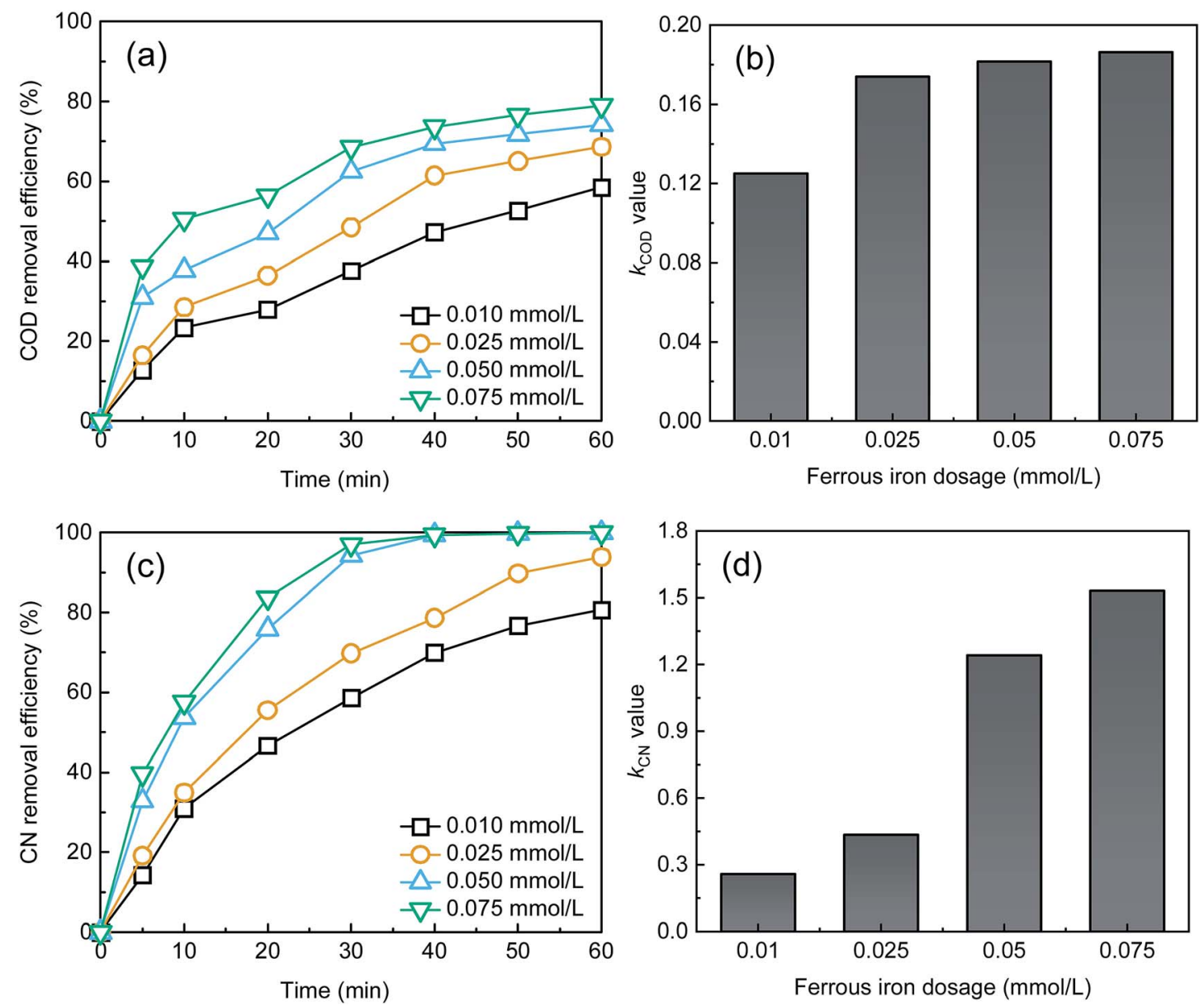

Fig. 3 Effect of $\mathrm{Fe}^{2+}$ dosage on (a) COD removal, (c) $\mathrm{CN}$ removal, and $k$ for (b) $\mathrm{COD}$ and (d) $\mathrm{CN}$. Conditions: $\mathrm{H}_{2} \mathrm{O}_{2}$ dose $=7.5 \mathrm{~mL} \mathrm{~L}^{-1}$ and initial pH $=5.0$. 

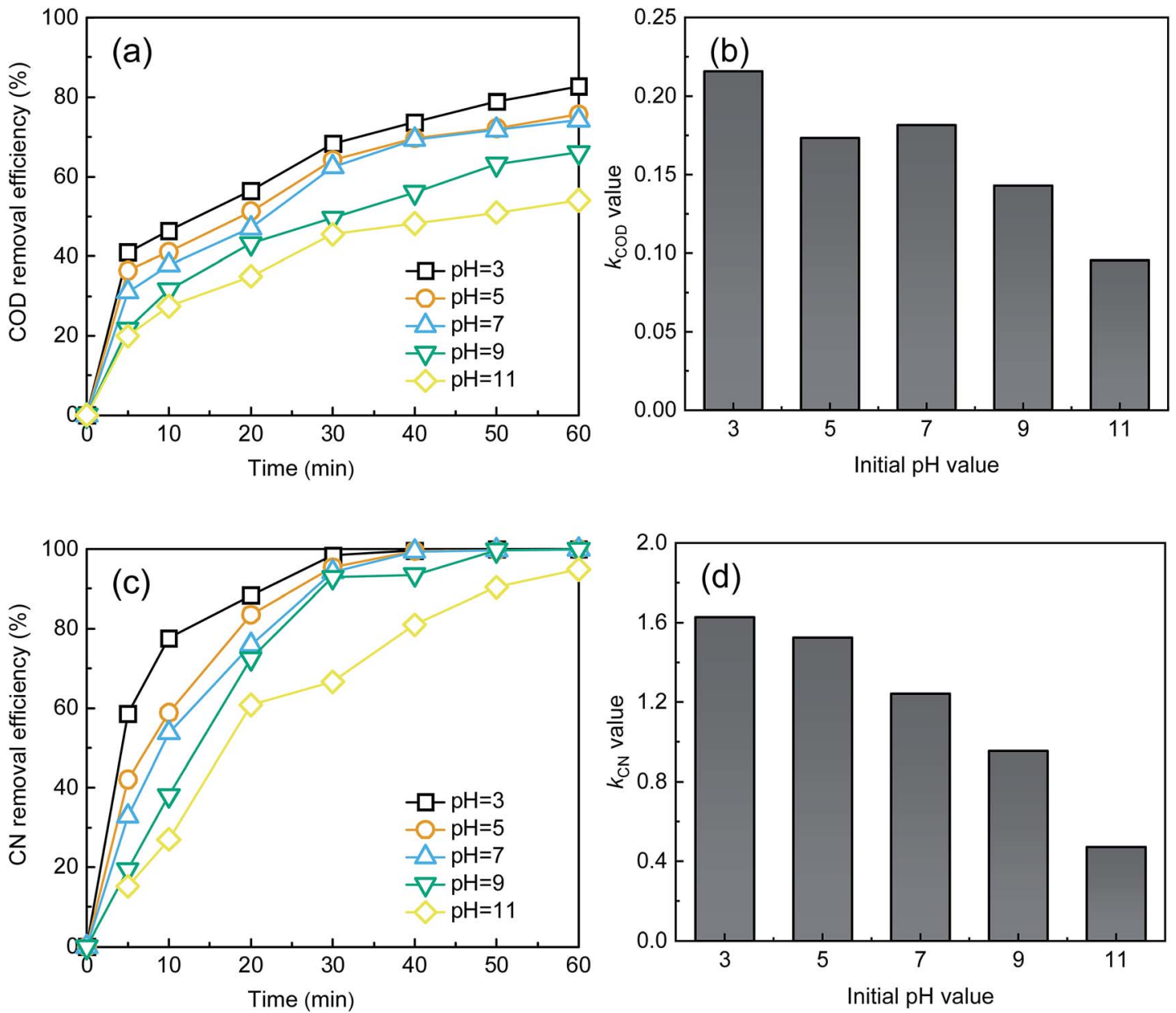

Fig. 4 Effect of initial pH on (a) COD removal, (c) CN removal, and $k$ for (b) $C O D$ and (d) CN. Conditions: $\mathrm{H}_{2} \mathrm{O}_{2}$ dose $=7.5 \mathrm{~mL} \mathrm{~L}$ and Fe $\mathrm{L}^{2+}$ dosage $=0.05 \mathrm{mM}$.

The single process, as shown in Fig. 5, yielded much lower treatment efficiencies. The COD removal efficiencies of single $\mathrm{Fe}^{2+}$, single $\mathrm{H}_{2} \mathrm{O}_{2}$, and single UV were $18.38 \%, 21.62 \%$, and 22.46, respectively. The CN removal efficiencies of single $\mathrm{Fe}^{2+}$, single $\mathrm{H}_{2} \mathrm{O}_{2}$, and single UV were $23.02 \%, 27.30 \%$, and $30.42 \%$, respectively. Likewise, the $k_{\mathrm{COD}}$ and $k_{\mathrm{CN}}$ value in the three single processes was significantly low. In the single $\mathrm{Fe}^{2+}$ and single UV lacking in oxidant, the main contribution to the removal of organics was iron colloids or UV light. ${ }^{37,38}$ In single $\mathrm{H}_{2} \mathrm{O}_{2}$ without catalysis, ROS production was limited. Hence, the single process cannot achieve a satisfactory treatment results for the above reasons.

The three binary processes (i.e., UV-Fe ${ }^{2+}$, Fenton, and UV$\mathrm{H}_{2} \mathrm{O}_{2}$ ) showed an enhanced treatment efficiency to a different extent. The most significant process, the $\mathrm{UV}-\mathrm{H}_{2} \mathrm{O}_{2}$ process, yielded $61.68 \%$ COD removal, $83.07 \% \mathrm{CN}$ removal, $0.13 \mathrm{~min}^{-1}$ of $k_{\mathrm{COD}}$ and $0.26 \mathrm{~min}^{-1}$ of $k_{\mathrm{CN}}$ at a 60 min reaction time. The $\mathrm{SE}$ of the UV- $\mathrm{H}_{2} \mathrm{O}_{2}$ process was 3.53 for COD removal and 4.34 for $\mathrm{CN}$ removal, which is higher than that of the $\mathrm{UV}-\mathrm{Fe}^{2+}$ and Fenton. A lack of oxidant is the main reason for the lower treatment efficiency of the UV-Fe ${ }^{2+}$ compared with the $\mathrm{UV}-\mathrm{H}_{2} \mathrm{O}_{2}$. Compared with $\mathrm{Fe}^{2+}$, a better catalysis effect will be achieved by the UV and more $\cdot \mathrm{OH}$ will be produced. Thus, the $\mathrm{UV}-\mathrm{H}_{2} \mathrm{O}_{2}$ process showed a much better treatment efficiency than that of the Fenton process. In the UV-Fenton process, the removal efficiencies of the COD and CN were $74.24 \%$ and $99.94 \%$, and the $k_{\mathrm{COD}}$ and $k_{\mathrm{CN}}$ were 0.18 and $1.24 \mathrm{~min}^{-1}$, respectively. The treatment results and reaction rate of UV-Fenton were higher than that of other control processes. The SE for COD and CN in the UV-Fenton process were 3.19 and 14.24 , respectively, which indicated a strong synergetic effect in the UV-Fenton process. In summary, the treatment efficiency of the UV-Fenton was satisfactory and this process provided an efficient treatment method for DDNP industrial wastewater.

\subsection{Alcohol quenching tests}

To study the reaction mechanism of the UV-Fenton process, alcohol quenching tests were carried out. TBA can react with . $\mathrm{OH}$ with a reaction rate of $3.8-7.6 \times 10^{8} \mathrm{M}^{-1} \mathrm{~s}^{-1}$, and has been used commonly as an $\cdot \mathrm{OH}$ quenching reagent. ${ }^{5,20,39,40}$ The $\mathrm{CN}$ removal efficiency and $k_{\mathrm{CN}}$ were used to evaluate the inhibition effect of the radical scavenger. The $\mathrm{UV}-\mathrm{H}_{2} \mathrm{O}_{2}$ process was applied in this test and compared to highlight the advantages of the UV-Fenton process. The results are shown in Fig. 6. 

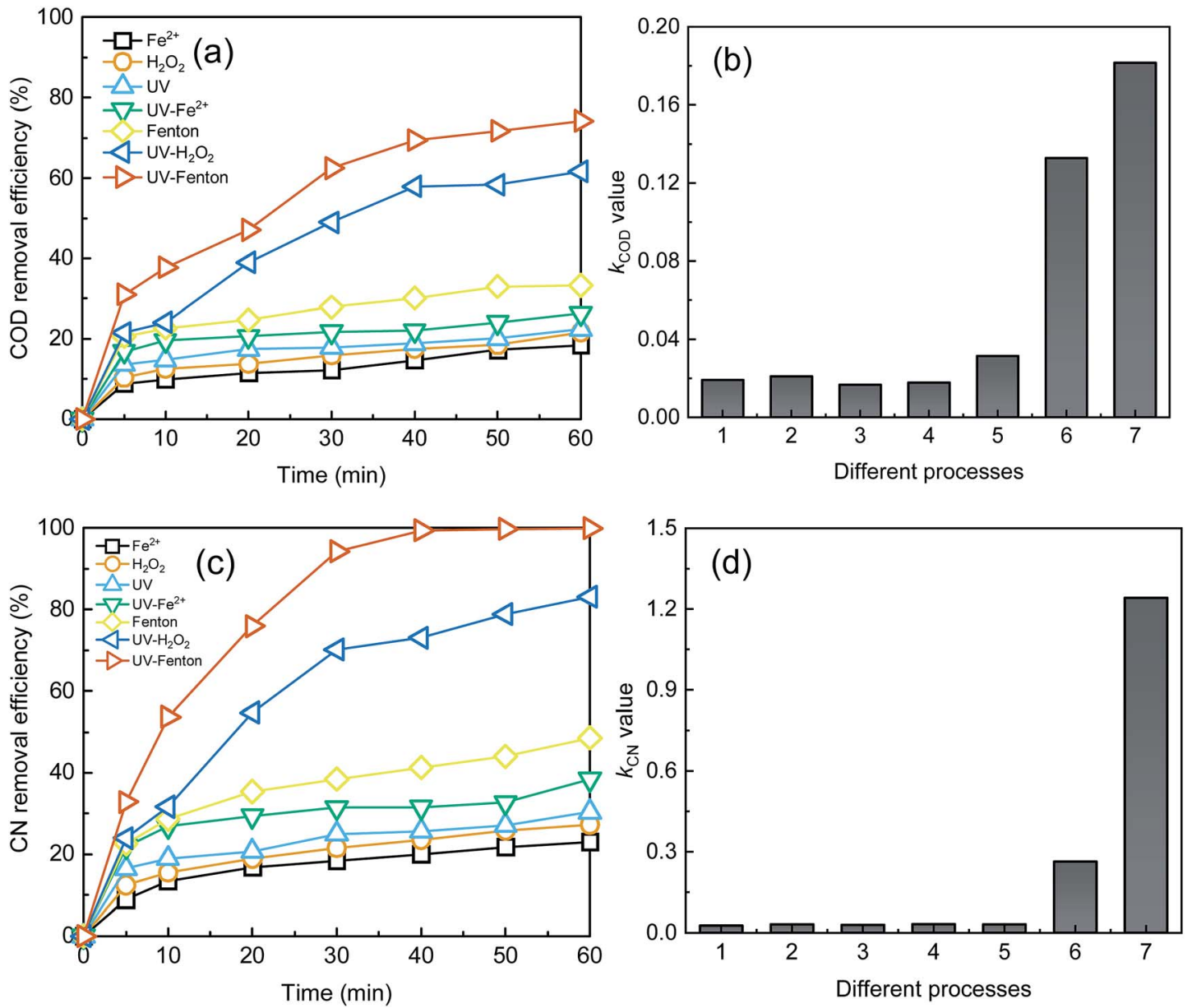

Fig. 5 Comparison of treatment efficiency of different processes: (a) COD removal, (c) CN removal, and $k$ for (b) COD and (d) CN. Conditions: $\mathrm{H}_{2} \mathrm{O}_{2}$ dose $=7.5 \mathrm{~mL} \mathrm{~L}^{-1}, \mathrm{Fe}^{2+}$ dosage $=0.05 \mathrm{mM}$, and initial $\mathrm{pH}=5$ ( 1 is single Fe $\mathrm{Fe}^{2+}, 2$ is single $\mathrm{H}_{2} \mathrm{O}_{2}, 3$ is single UV, 4 is UV-Fe $\mathrm{Fe}^{2+}, 5$ is Fenton, 6 is $\mathrm{UV}-\mathrm{H}_{2} \mathrm{O}_{2}$, and 7 is UV-Fenton).

As shown in Fig. 6, after adding TBA to the UV-Fenton and $\mathrm{UV}-\mathrm{H}_{2} \mathrm{O}_{2}$ processes, a noticeable inhibition effect was obtained. At a reaction time of 40 minutes, the $\mathrm{CN}$ removal efficiencies of UV-Fenton and UV- $\mathrm{H}_{2} \mathrm{O}_{2}$ decreased to $61.65 \%$ and $49.38 \%$ from $99.36 \%$ and $70.04 \%$, respectively, and $k_{\mathrm{CN}}$ decreased from 1.24 and $0.26 \mathrm{~min}^{-1}$ to 0.17 and $0.12 \mathrm{~min}^{-1}$, respectively. Therefore, .OH was important in the two processes. In addition, in terms of whether $\mathrm{CN}$ removal or $k_{\mathrm{CN}}$ change, a stronger inhibition effect was found in the UV-Fenton process. The results indicated that more $\cdot \mathrm{OH}$ was produced in the UV-Fenton process.
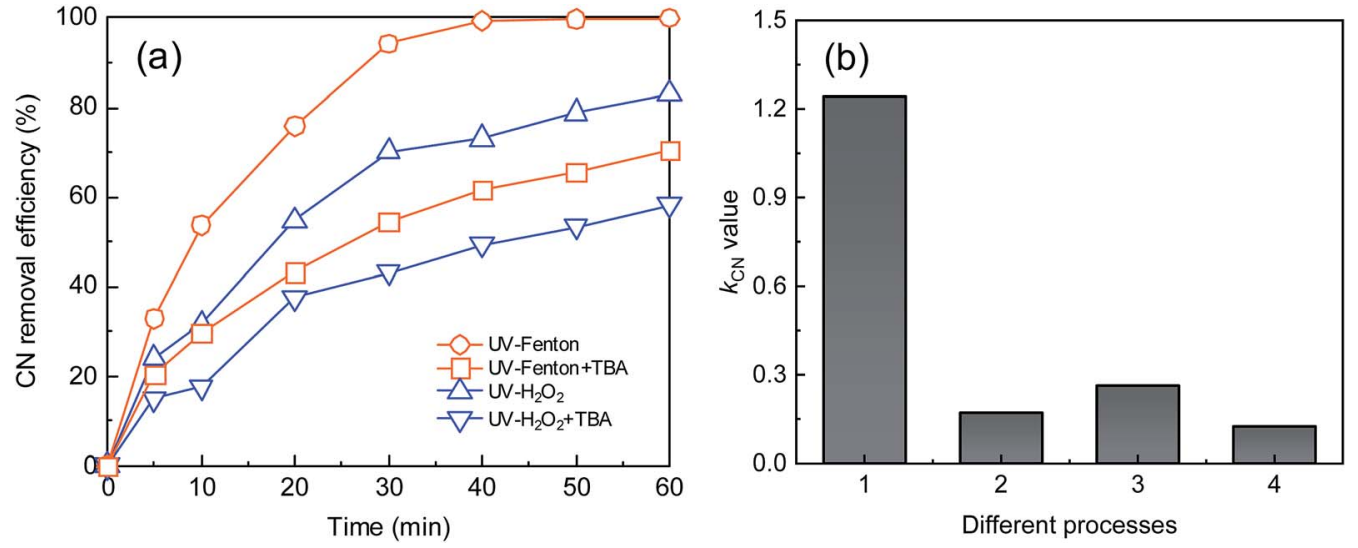

Fig. 6 Effect of TBA as radical scavenger on treatment efficacy of UV-Fenton and UV- $\mathrm{H}_{2} \mathrm{O}_{2}$ processes that treat DDNP industrial wastewater. Conditions: $\mathrm{H}_{2} \mathrm{O}_{2}$ dose $=7.5 \mathrm{~mL} \mathrm{~L}^{-1}, \mathrm{Fe}^{2+}$ dosage $=0.05 \mathrm{mM}$, and initial $\mathrm{pH}=5$ ( 1 is UV-Fenton, 2 is UV-Fenton with TBA added, 3 is UV- $\mathrm{H}_{2} \mathrm{O}_{2}$, and 4 is $U V-\mathrm{H}_{2} \mathrm{O}_{2}$ with TBA added). 

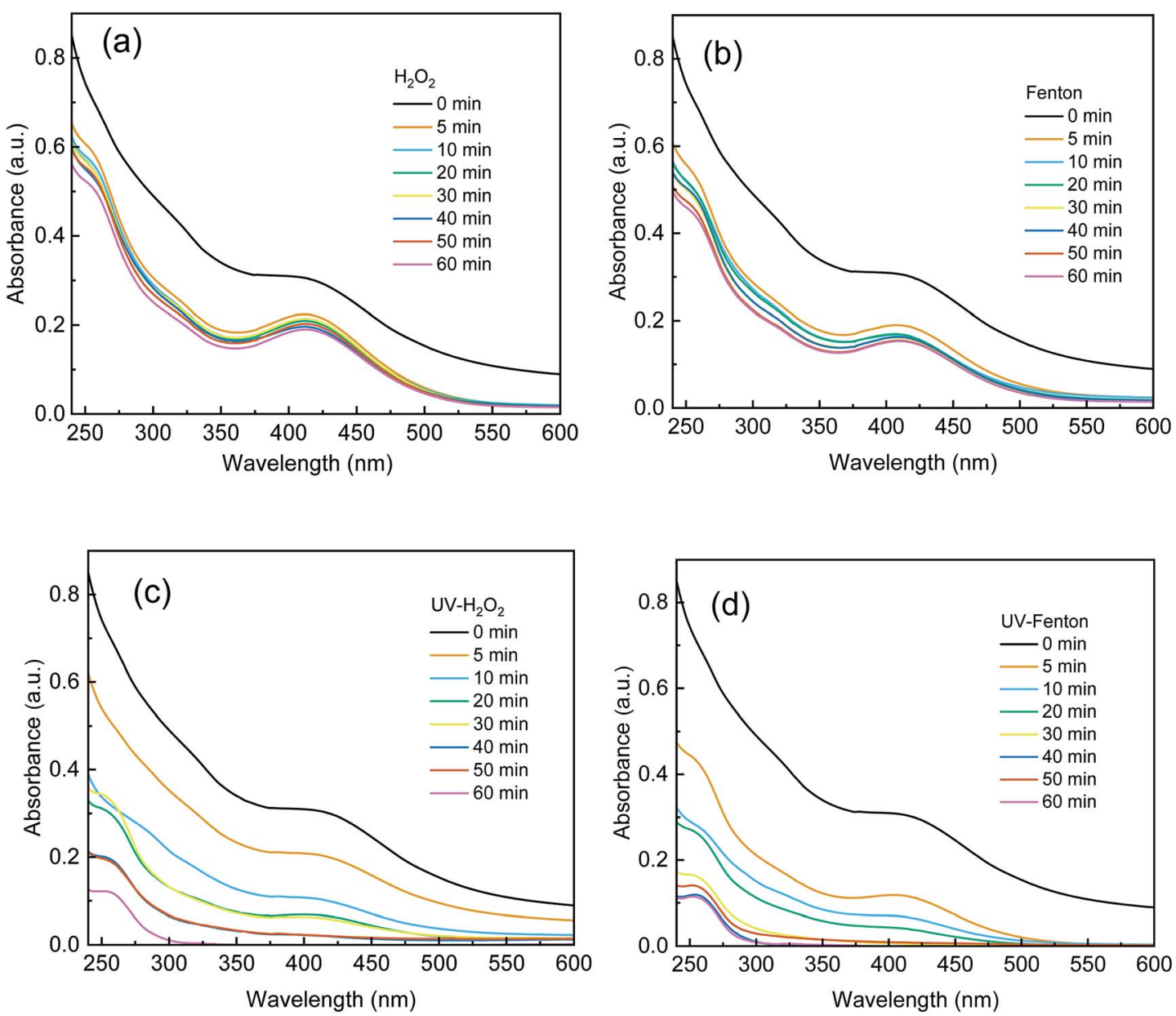

Fig. 7 UV-Vis spectra of effluent at different reaction times from different processes that treat DDNP industrial wastewater. Conditions: $\mathrm{H}_{2} \mathrm{O}_{2}$ dose $=7.5 \mathrm{~mL} \mathrm{~L}^{-1}, \mathrm{Fe}^{2+}$ dosage $=0.05 \mathrm{mM}$, and initial $\mathrm{pH}=5$.

UV and $\mathrm{Fe}^{2+}$ together can better catalyze $\mathrm{H}_{2} \mathrm{O}_{2}$ and more ROS was produced.

\subsection{UV-Vis analysis}

The absorbance of each sample from $240 \mathrm{~nm}$ to $600 \mathrm{~nm}$ was recorded and is shown in Fig. 7. UV-Vis was used to characterize the degradation of organics in DDNP industrial wastewater in the different processes. In Fig. 7, a strong absorbance was observed in the ultraviolet- and visible-light regions of the untreated DDNP industrial wastewater $(0 \mathrm{~min})$. The absorbance from $200 \mathrm{~nm}$ to $250 \mathrm{~nm}$ was assigned to the $\pi-\pi^{*}$ transition of the benzene rings and nitro group substances. ${ }^{2}$ The absorbance from $350 \mathrm{~nm}$ to $450 \mathrm{~nm}$ was assigned to the diazo group substances. $^{2}$

As shown in Fig. 7a and b, after the single $\mathrm{H}_{2} \mathrm{O}_{2}$ and Fenton processes for $60 \mathrm{~min}$, the effluent still showed a strong absorbance and the absorbance from $350 \mathrm{~nm}$ to $450 \mathrm{~nm}$ was relatively strong. Therefore, the single $\mathrm{H}_{2} \mathrm{O}_{2}$ and Fenton processes cannot degrade and destroy refractory organics in DDNP industrial wastewater effectively. As shown in Fig. $7 \mathrm{c}$ and d, a much more considerable decrease of absorbance can be observed in the UV$\mathrm{H}_{2} \mathrm{O}_{2}$ and UV-Fenton processes. The absorbance of effluents in the UV- $\mathrm{H}_{2} \mathrm{O}_{2}$ and UV-Fenton processes at 60 min was close to 0 .
The results prove that recalcitrant organics that contain a benzene-ring, nitro group, and diazo group in DDNP industrial wastewater in the UV- $\mathrm{H}_{2} \mathrm{O}_{2}$ and UV-Fenton processes can be degraded significantly. In addition, a faster and more thorough decrease of absorbance was presented by the UV-Fenton process, which can be attributed to the fact that the UVFenton process can produce more $\cdot \mathrm{OH}$ during the early stage of reaction and therefore exhibited a higher treatment efficiency than the $\mathrm{UV}-\mathrm{H}_{2} \mathrm{O}_{2}$.

\subsection{Biodegradability analysis}

DDNP industrial wastewater has an extremely low biodegradability (BOD/COD ratio) because of the presence of DDNP and its derivatives, which are biotoxic and biorefractory. The biodegradability of effluent from different processes that treat DDNP industrial wastewater is presented in Fig. 8.

As shown in Fig. 8, the biodegradability of untreated DDNP industrial wastewater is only 0.054 , whereas the effluent biodegradability increased to a different degree. After Fenton, $\mathrm{UV}-\mathrm{H}_{2} \mathrm{O}_{2}$, and UV-Fenton treatment, the effluent biodegradability was $0.11,0.33$, and 0.48 . The results indicate that these processes can degrade the refractory organics with different efficacies. Some biorefractory substances in treated effluent 


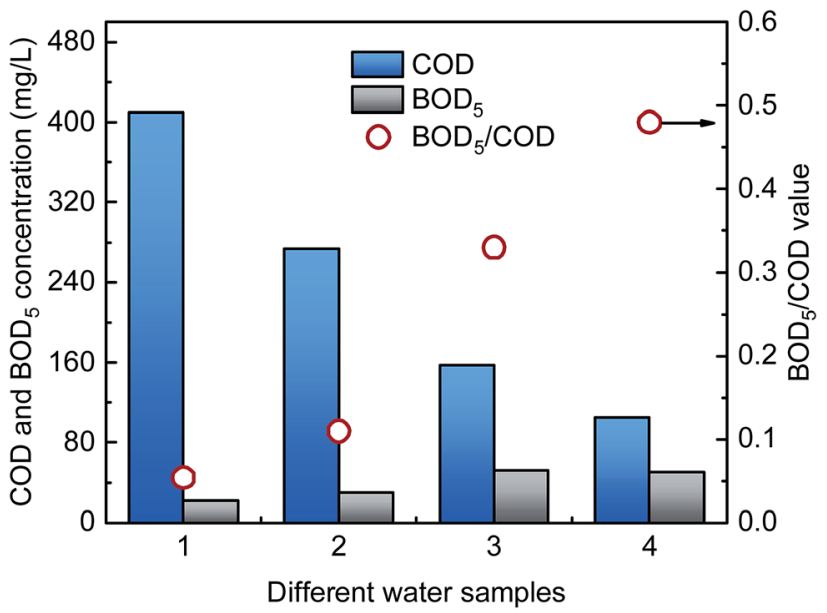

Fig. 8 Variation of $\mathrm{COD}$ and $\mathrm{BOD}$ concentrations and biodegradability. Conditions: $\mathrm{H}_{2} \mathrm{O}_{2}$ dose $=7.5 \mathrm{~mL} \mathrm{~L}^{-1}, \mathrm{Fe}^{2+}$ dosage $=0.05 \mathrm{mM}$, initial $\mathrm{pH}=5$, and reaction time $=60 \mathrm{~min}$ ( 1 is untreated DDNP industrial wastewater, 2 is Fenton, 3 is $\mathrm{UV}-\mathrm{H}_{2} \mathrm{O}_{2}$, and 4 is UV-Fenton).

were degraded and transformed to biodegradable organics, especially from UV-Fenton treatment of DDNP industrial wastewater.

\subsection{Energy consumption}

To evaluate the electrical energy consumption of the UV-Fenton, EEC was used and calculated according to eqn (4). The UV and $\mathrm{UV}-\mathrm{H}_{2} \mathrm{O}_{2}$ processes use UV lamps that consume electricity, and the two processes were analyzed and compared with the UVFenton process. The results are shown in Fig. 9.

As shown in Fig. 9, the EEC of the three processes increased with reaction time. In the single UV process, the EEC increased from $48.97 \mathrm{~kW} \mathrm{~h} \mathrm{~L}^{-1}$ at $5 \mathrm{~min}$ to $339.86 \mathrm{~kW} \mathrm{~h} \mathrm{~L}^{-1}$ at $60 \mathrm{~min}$. At $60 \mathrm{~min}$, the EEC of the UV- $\mathrm{H}_{2} \mathrm{O}_{2}$ and UV-Fenton were $90.07 \mathrm{~kW} \mathrm{~h}$

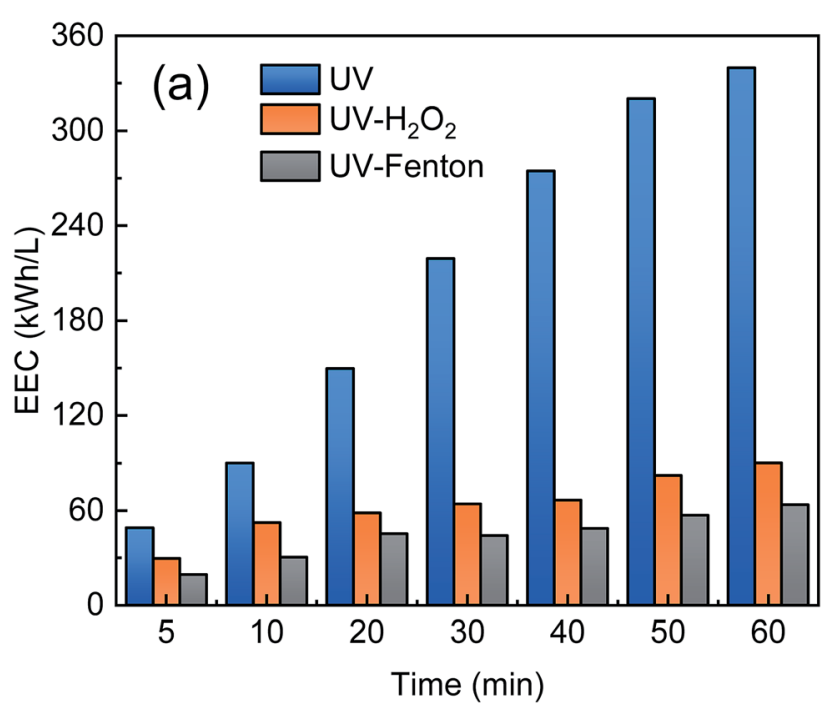

Fig. 9 Electrical energy consumption of UV, UV- $\mathrm{H}_{2} \mathrm{O}_{2}$, and UV-Fenton when treating DDNP industrial wastewater. Conditions: $\mathrm{H}_{2} \mathrm{O}_{2}$ dose $=7.5 \mathrm{~mL} \mathrm{~L}^{-1}, \mathrm{Fe}^{2+}$ dosage $=0.05 \mathrm{mM}$, initial $\mathrm{pH}=5$, and reaction time $=60 \mathrm{~min}$.
$\mathrm{L}^{-1}$ and $63.67 \mathrm{~kW} \mathrm{~h} \mathrm{~L}^{-1}$, which are much lower than that of the single UV. Therefore, the UV-Fenton process showed a remarkable economic advantageous over UV and $\mathrm{UV}-\mathrm{H}_{2} \mathrm{O}_{2}$. Electricity savings of $162.08 \mathrm{~kW} \mathrm{~h}$ and $19.27 \mathrm{~kW} \mathrm{~h}$ will be achieved for every liter of DDNP industrial wastewater that was treated by the UVFenton process.

\section{Conclusions}

The UV-Fenton process was applied to the treatment of refractory organics in DDNP industrial wastewater. Increasing $\mathrm{H}_{2} \mathrm{O}_{2}$ and $\mathrm{Fe}^{2+}$ dosages enhanced the treatment efficacy of the UVFenton process, and the alkaline condition depressed the treatment capacity of the UV-Fenton process. Under optimized conditions of a $\mathrm{H}_{2} \mathrm{O}_{2}$ dose $=7.5 \mathrm{~mL} \mathrm{~L}^{-1}, \mathrm{Fe}^{2+}$ dosage $=$ $0.05 \mathrm{mM}$, initial $\mathrm{pH}=5$, and reaction time $=60 \mathrm{~min}$, the removal efficiencies of COD and $\mathrm{CN}$ were $74.24 \%$ and 99.94, respectively, and the $k_{\mathrm{COD}}$ and $k_{\mathrm{CN}}$ were 0.18 and $1.24 \mathrm{~min}^{-1}$. Controlled experiments showed that a much better treatment efficiency was obtained, and a strong synergetic effect was found in the UV-Fenton process. $\cdot \mathrm{OH}$ plays an important role in the $\mathrm{UV}-\mathrm{H}_{2} \mathrm{O}_{2}$ and UV-Fenton processes. In the UV-Fenton process, more $\cdot \mathrm{OH}$ was produced and therefore, refractory organics were degraded more thoroughly. Spectral analysis indicated that refractory organics that contain a benzene-ring, a nitro group, and a diazo group can be degraded by the UVFenton process, and therefore, the biodegradability of the wastewater can be improved significantly to 0.48 from 0.054 . UV-Fenton exhibited an energy saving and economic advantage compared with single UV and UV- $\mathrm{H}_{2} \mathrm{O}_{2}$.

\section{Conflicts of interest}

There are no conflicts to declare.

\section{Acknowledgements}

Authors gratefully acknowledge the financial support from Science \& Technology Department of Sichuan Province (201986).

\section{References}

1 Z.-W. Yang, Y.-C. Liu, D.-C. Liu, L.-W. Yan and J. Chen, J. Hazard. Mater., 2010, 177, 938-943.

2 Y. Yuan, B. Lai and Y.-Y. Tang, Chem. Eng. J., 2016, 283, 15141521.

3 J. Cao, Z. Xiong, Y. Yuan, B. Lai and P. Yang, RSC Adv., 2016, 6, 94467-94475.

4 J. Zhai and Y. Wang, Procedia Environ. Sci., 2013, 18, 632-637.

5 Z. Gu, W. Chen, Q. Li and A. Zhang, Chemosphere, 2019, 215, 82-91.

6 Z. Xiong, H. Zhang, W. Zhang, B. Lai and G. Yao, Chem. Eng. J., 2019, 359, 13-31.

7 L.-l. Wei, W.-m. Chen, Q.-b. Li, Z.-p. Gu and A.-p. Zhang, RSC Adv., 2018, 8, 20603-20611. 
8 J. Khatri, P. V. Nidheesh, T. S. Anantha Singh and M. Suresh Kumar, Chem. Eng. J., 2018, 348, 67-73.

9 D. B. Miklos, C. Remy, M. Jekel, K. G. Linden, J. E. Drewes and U. Hübner, Water Res., 2018, 139, 118-131.

10 M. Y. Kilic, W. H. Abdelraheem, X. He, K. Kestioglu and D. D. Dionysiou, J. Hazard. Mater., 2019, 367, 734-742.

11 W. Chen, A. Zhang, Z. Gu and Q. Li, Chem. Eng. J., 2018, 354, 680-691.

12 C. Chen, H. Feng and Y. Deng, Water Res., 2019, 153, 100107.

13 T. Sruthi, R. Gandhimathi, S. T. Ramesh and P. V. Nidheesh, Chemosphere, 2018, 210, 38-43.

14 R. Poblete, I. Oller, M. I. Maldonado and E. Cortes, J. Environ. Manage., 2019, 232, 45-51.

15 M.-h. Zhang, H. Dong, L. Zhao, D.-x. Wang and D. Meng, Sci. Total Environ., 2019, 670, 110-121.

16 M. Cheng, G. Zeng, D. Huang, C. Lai, P. Xu, C. Zhang and Y. Liu, Chem. Eng. J., 2016, 284, 582-598.

17 R. L. Siegrist, Principles and practices of in situ chemical oxidation using permanganate, Battelle Press, 2001.

18 B. G. Petri, R. J. Watts, A. L. Teel, S. G. Huling and R. A. Brown, in In situ chemical oxidation for groundwater remediation, Springer, 2011, pp. 33-88.

19 R. J. Watts and A. L. Teel, Water Res., 2019, 159, 46-54.

20 W. R. Haag and C. D. Yao, Environ. Sci. Technol., 1992, 26, 1005-1013.

21 C.-Y. Hu, Y.-Z. Hou, Y.-L. Lin, Y.-G. Deng, S.-J. Hua, Y.-F. Du, C.-W. Chen and C.-H. Wu, Chemosphere, 2019, 229, 602-610.

22 D. B. Miklos, W. L. Wang, K. G. Linden, J. E. Drewes and U. Hübner, Chem. Eng. J., 2019, 362, 537-547.

23 X. Da, H. Ji, Z. Zhao, R. Lan, T. Li and J. Ma, Sep. Purif. Technol., 2019, 213, 500-506.

24 X. Miao, H. Dai, J. Chen and J. Zhu, Sep. Purif. Technol., 2018, 200, 36-43.
25 A. Fischbacher, C. von Sonntag and T. C. Schmidt, Chemosphere, 2017, 182, 738-744.

26 W. Barb, J. Baxendale, P. George and K. Hargrave, Trans. Faraday Soc., 1951, 47, 462-500.

27 H. Dai, S. Xu, J. Chen, X. Miao and J. Zhu, Chemosphere, 2018, 199, 147-153.

28 J. J. Pignatello, D. Liu and P. Huston, Environ. Sci. Technol., 1999, 33, 1832-1839.

29 E. Rott, R. Minke, U. Bali and H. Steinmetz, Water Res., 2017, 122, 345-354.

30 N. Hassanshahi and A. Karimi-Jashni, Ecotoxicol. Environ. Saf., 2018, 161, 683-690.

31 Water quality-Determination of the chemical oxygen demandDichromate method (HJ 828-2017).

32 M. Khandarkhaeva, A. Batoeva, D. Aseev, M. Sizykh and O. Tsydenova, Ecotoxicol. Environ. Saf., 2017, 137, 35-41.

33 N. Daneshvar, A. Aleboyeh and A. Khataee, Chemosphere, 2005, 59, 761-767.

34 Y. Zhang, N. Klamerth, P. Chelme-Ayala and M. Gamal ElDin, Environ. Sci. Technol., 2016, 50, 10535-10544.

35 O. Legrini, E. Oliveros and A. Braun, Chem. Rev., 1993, 93, 671-698.

36 W. Barb, J. Baxendale, P. George and K. Hargrave, Trans. Faraday Soc., 1951, 47, 591-616.

37 H. Gong, W. Chu, S. H. Lam and A. Y.-C. Lin, Chemosphere, 2017, 167, 415-421.

38 I. Velo-Gala, J. J. López-Peñalver, M. Sánchez-Polo and J. Rivera-Utrilla, Chem. Eng. J., 2014, 241, 504-512.

39 G. V. Buxton, W. P. Greenstock and A. B. Helman, J. Phys. Chem. Ref. Data, 1988, 17, 513-886.

40 C. Qi, G. Yu, J. Huang, B. Wang, Y. Wang and S. Deng, Chem. Eng. J., 2018, 353, 490-498. 